\title{
Lipid Profiling of the Carob Fruit (Ceratonia Siliqua L.) Using GC/LC/QTOF Accurate Mass Spectrometry
}

\author{
Thao Nguyen¹, Mario Aparicio² and Mahmoud A. Saleh ${ }^{1 *}$ \\ ${ }^{1}$ Department of Chemistry, Texas Southern University, 3100 Cleburne Street, Houston, TX 77004, USA \\ ${ }^{2}$ Agilent Technologies, Inc, 3750 Brookside Parkway, Suite 100, Alpharetta, GA 30022, USA
}

Received: October 13, 2016; Accepted: December 16, 2016; Published: January 03, 2017

*Corresponding authors: Mahmoud A. Saleh, PhD, Professor of chemistry, College of Science, Engineering and Technology, Texas Southern University, 3100 Cleburne Street, Houston, Texas 77004 USA; Tel: 7133131912 (office), 7138515023 (cell); Fax: 7133137824 ; E mail: saleh_ ma@tsu.edu

\begin{abstract}
The carob tree (Ceratonia siliqua L.) is a native of the Mediterranean basin with several applications in the food, textile and cosmetics industries and the pods of the carob fruit have long been used as a feed for livestock and in human nutrition, including sweets, biscuits and processed drinks, because of its high sugar content and low price. This work serves as the first step towards a comprehensive metabolomics characterization of Ceratonia siliqua L. Gas chromatography and liquid chromatography coupled with quadrupole time of flight mass spectrometry were used to profile and quantify lipids in the whole pod/pericarp of the carob fruits. Crude lipids were extracted from the carob powder using $\mathrm{CO}_{2}$ supercritical fluid extraction in a yield of $2.0 \%$. A total of 14 fatty acids, 5 phospholipids, 10 triacylglycerol, 8 steroids as well as hydrocarbons and 16 head space volatile compounds were identified and quantified.
\end{abstract}

Keywords: Fatty acids; Head space; Triglycerides; Phospholipids; Unsaponifiable matters; Leguminosae

\section{Introduction}

The carob tree (Ceratonia siliqua L.) is a native of the Mediterranean basin with several applications in the food, textile and cosmetics industries [1]. It belongs to the Caesalpinaceae sub-family of the family Leguminoseae [2].The pods of the carob fruit have long been used as a feed for livestock and in human nutrition, including sweets, biscuits and processed drinks, because of its high sugar content and low price [3]. The world production of carob pods is 374,800 to 441,000 tones/year, the leading producer countries are Spain followed by Italy, Portugal, Morocco, Greece, Cyprus, Turkey and Algeria [4,5]. Carob pods are rich source of natural antioxidants which may, by different mechanisms, act as an effective defense against reactive oxygen species including free radicals such as superoxide anion and hydroxyl radicals, and non-free radical species such as hydrogen peroxide. The two principal components of the carob fruit are the pulp and seed. The seeds represent $10 \%$ of the weight of the fruit and the pulp represent the other $90 \%$ of the fruit, crushed pods may be used to make a beverage, liqueur and syrup [6] Image of the carob pods are shown in Figure 1.

Lipids are essential metabolites in cells and they fulfill a variety of functions which include structural components of cellular membranes, energy storage, cell signaling, and membrane trafficking [7]. In plants, alterations in the composition of lipids have been observed during cold/heat stress, nutrient deficiencies, aging and response to pathogen attack [8]. Lipids are divided into several classes based on their chemical structures: fatty acyls, glycerol lipids, glycerol phospholipids, sphingolipids, sterol lipids, prenol lipids, saccharolipids and polyketides [9]. In order to understand the function of lipids in biological systems, it is important to profile the diverse lipid species present in any given organism and quantify their levels. Recent technological advances in tandom chromatography and mass spectrometry have enabled high-throughput, systematic profiling of lipid species known as lipidomics $[7,10]$. This study aims to use accurate mass GCQTOF and LCQTOF to profile and quantify levels of lipid classes in the pods of the carob fruits as a first step towards understanding its lipidome.

\section{Experimental}

\section{Plant material}

Carob pods were collected from the seed department of

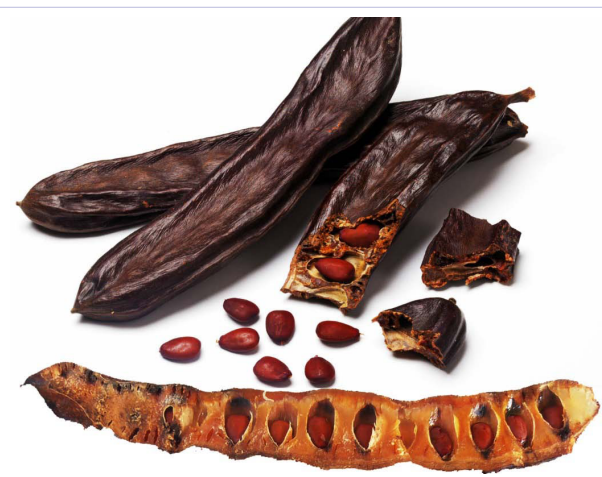

Figure 1: Image of the carob pods that was used in this investigation 
the agricultural research center, Ministry of Agriculture, Giza, Egypt in the summer of 2016 and kindly authenticated by the agricultural botany department of the faculty of agriculture, university of Cairo. The pods were dried in the dark smashed and seeds were mechanically removed and the pulps were grounded using a grinder (Sunbeam Osterizer blender, Boca Raton, USA) to fine powder.

\section{Extraction of crude lipids}

$\mathrm{CO}_{2}$ supercritical fluid extraction was done using the SFT-10 Constant Flow /Constant Pressure

Dual Piston Pump SFE unit (Proras, Rome, Italy). The extraction basket utilized in this study had an internal volume of $0.5 \mathrm{~L}$ and, for each test, batches of about $65 \mathrm{~g}$ of carob pods were placed in the basket and utilized for the extraction. Pressure and temperature were kept constant at 500 bar and a temperature of $50 \mathrm{C}$ yielding a light yellow oil in $2 \%$ by weight.

\section{Preparation of fatty acids methyl esters (FAMEs)}

The transesterification was carried as we described before [11] by adding $10 \mathrm{mg}$ of the lipid extract to $2 \mathrm{~mL}$ of $2 \% \mathrm{BF} 3$ in methanol, mixed by vortex and placed on the heating block at $75{ }^{\circ} \mathrm{C}$ for $1 \mathrm{~h}$. After cooling down to room temperature, $1 \mathrm{~mL}$ of saturated sodium chloride solution was added to step the reaction and FAMES were extracted in $2 \mathrm{~mL}$ of iso-octane, passed through anhydrous sodium sulfate and transferred to GC vials for GCMS analysis.

\section{Accurate mass GC-QTOF}

Agilent 7200 accurate mass GCQTOF System was used for analyzing FAMES samples. GC separation was done using a BPX90 SGE Analytical Science column $30 \mathrm{~m}$ x $0.25 \mathrm{~mm} \times 0.25 \mu \mathrm{m}$ column (SGE Analytical Science, Texas) run under average velocity of 63.9 $\mathrm{cm} / \mathrm{sec}$ with a hold up time of $1 \mathrm{~min}$. Temperature programming started at $75{ }^{\circ} \mathrm{C}$ held for $2 \mathrm{~min}$ and heated up to $200{ }^{\circ} \mathrm{C}$ at a rate of $5{ }^{\circ} \mathrm{C} / \mathrm{min}$, held at $200^{\circ} \mathrm{C}$ for $3 \mathrm{~min}$. Total run time was $30 \mathrm{~min}$; solvent delay $4 \mathrm{~min}$; equilibration time $3 \mathrm{~min}$. His collision gas $1.5 \mathrm{~mL} / \mathrm{min}$; injected volume $1 \mu \mathrm{L}$; split mode 10:1. Mass spectral acquisitions were separately performed in EI mode and CI mode using methane as the reagent gas. The measurements and postrun analyses were controlled by the software Mass Hunter Qualitative Analysis B.07.00 SP1 [12].FAMES was identified based on their retention times and their accurate mass data Their electron ionization fragmentation and mass spectral data were also searched using Wiley10NIST mass spectral database.

\section{LC-QTOF}

Agilent 6530 accurate mass LC-QTOF system equipped with 1290 binary pump, Phenomenexkinetex C18 $100 \mathrm{~mm} x$ $3.0 \mathrm{~mm} 2.6 \mu \mathrm{m}$ columns. Solvents A was made of isopropanol; $\mathrm{B}$ acetonitrile run in a gradient protocol starting at $50 \% \mathrm{~A}, 50 \%$ B with a flow $0.2 \mathrm{~mL} / \mathrm{min}$ reaching $100 \%$ solvent $\mathrm{A}$ at $10.0 \mathrm{~min}$ from the start, and held at $100 \% \mathrm{~A}$ for additional $5 \mathrm{~min}$. Injection volume was $2 \mu \mathrm{L}$; mass range from $100 \mathrm{~m} / \mathrm{z}$ to $1500 \mathrm{~m} / \mathrm{z}$, with a total run time of $30 \mathrm{~min}$. The LC-QTOF instrument was operated under the following conditions: Ion source ESI + Agilent Jet
Stream Technology in positive ionization mode. Instrument parameters were set as follows: sheath gas temperature, $350^{\circ} \mathrm{C}$; sheath gas flow, $8 \mathrm{~L} / \mathrm{min}$; nebulizer, $20 \mathrm{psi}$; dry gas temperature, $300{ }^{\circ} \mathrm{C}$; dry gas flow, $5 \mathrm{~L} / \mathrm{min}$; and capillary entrance Voltage, 3500 V. Fragmentor and Skimmer 1 were operated at 190 and 65 $\mathrm{V}$, respectively. The MS scan data were collected at a rate of 1.02 spectra/s in the range of $\mathrm{m} / \mathrm{z}$ 100-2000.All the MS data were collected with Mass Hunter Data Acquisition B.06.00 (Agilent Technologies), and Mass Hunter Qualitative Analysis B.06.00 SP1 (Agilent Technologies) was applied to identify lipid species. All EICs were obtained with $10 \mathrm{ppm} \mathrm{m/z} \mathrm{expansion.} \mathrm{Microsoft}$ Office Excel 2013(Microsoft, Redmond, WA, USA) were used for statistical data analysis and data visualization [12].

\section{LC-QTOF MS/MS experiment}

MS/MS experiments were carried out as we described before [12] at energies of $50 \mathrm{eV}$, run time $15 \mathrm{~min}$; ion source: positive; source gas temperature $300{ }^{\circ} \mathrm{C}$; drying gas $3.0 \mathrm{~L} / \mathrm{min}$; nebulizer 15 psig; sheath gas temperature $125{ }^{\circ} \mathrm{C}$; sheath gas flow $3.0 \mathrm{~L} /$ min; dual AJS ESI; V cap $4000 \mathrm{~V}$; capillary $0.063 \mu \mathrm{A}$; nozzle Voltage $0 \mathrm{~V}$; chamber $5.33 \mu \mathrm{A}$; ms/ms mass range $100 \mathrm{~m} / \mathrm{z}$ to $1600 \mathrm{~m} / \mathrm{z}$; acquisition rate 1 spectrum/s; acquisition time 1000 $\mathrm{ms} /$ spectrum; 13,503 transients/spectrum; auto recalibration reference mass window, detection window 100 ppm; minimum height 1000 counts; polarity type: positive; offset: $15 ; \mathrm{ms} / \mathrm{ms}$ absolute threshold 5; reference threshold 0.01\%.

\section{Head space analysis}

Head space analysis was carried out on the dry carob powder (1g) using Agilent 7890B/5975C GCMS system equipped with Agilent 7697A head space sampler. GCMS conditions were the same as those described above.

\section{Analysis of unsaponifiable matters}

Unsaponifiable matters from the lipid extract were analyzed using the standard AOCS method [13]. Oil samples were saponified by refluxing with $0.5(\mathrm{~N})$ ethanolic potassium hydroxide for 2 hours on a water bath the unsap matters were extracted with petroleum ether, washed with water, dried over anhydrous sodium sulfate and analyzed by GCMS at the same condition described above.

\section{Results and Discussion}

Crude lipids extracts were obtained from dried carob powder using $\mathrm{CO}_{2}$ SFE extraction as shown in the experimental sections at a Yield $(\mathrm{w} / \mathrm{w})$ of $1.98 \%$.

\section{Fatty acids composition}

Fatty acid methyl esters (FAMES) relative percentage composition is shown in Table 1. FAMES were identified based on their retention times and their accurate mass data in the chemical ionization mode and by their electron ionization fragmentation mass spectral data by searched using Wiley10NIST mass spectral database. GCMS analysis of the fatty acids methyl esters (FAMES) was achieved with base line resolution as shown in Figure 2. $32 \%$ of the identified fatty acids were saturated fatty acid with palmitic acid (16:0) as the most abundant fatty acid contributing 
more than $21 \%$ of the total fatty acids, stearic acid (18:0) was found at almost $4 \%$ of the total, all other saturated fatty acids were found as minor components contributing only $1-2 \%$ of the total fatty acids. Relative concentration of unsaturated fatty acids was $63 \%$ of the total and was made primarily of oleic acid Z-9octadecenoic acid (18:1)) with an overall concentration of 55\%. Z,Z-9,12-octadecadienoic acid (18:2) was found at concentration of $6.5 \%$.Other minor concentrations of fatty acids including $\Omega-3$ fatty acids C18:3, C22:2 and C24:3 as well as other unidentified compounds were less than $4 \%$ of the total but no individual compound exceeded $0.05 \%$.

\section{Identification of triacylglycerols (TAGs)}

TAGs composition in the crude lipid extract was invigilated using the accurate mass LC-QTOF system. Ten major TAGs were identified as shown in Figure 3. Ions were identified as positive ion sodium adducts with exact masses of 879.7426, 901.7251, 903.7418, 907.7743, 909.7891, 935.8055, 937.8205, 965.8523, 967.8679 and 993.8852. Although the ion $[\mathrm{M}+\mathrm{Na}]^{+}$with the accurate mass equivalent to 879.7426 represent 56 possible TAG isomers this number can be reduced to 14 ,by eliminating TAGs that have any fatty acid that was not detected in the oil (Table 2).Similarly, the accurate mass of 901.7256 represents 186 possible TAG isomers, this number can be reduced by eliminating TAGs that have any fatty acid that was not detected in the oil (Table 2).

\section{Determination of regioisomers by MS/MS}

There are large number of different triacylglycerols species (TAGs), which differ in the total length of acyl chains and their degree of unsaturation. Isobaric TAGs are designated by having the same number of carbon atoms and double bonds possessing acylchains with different length, position and configuration of double bonds. The acylchain may be located in three different

Table 1.Fatty acid methyl esters (FAMES) composition and relative percentage of lipid extract of the carob pods. Peak numbers are those shown in Figure 2.

\begin{tabular}{|c|c|c|c|c|}
\hline Peak \# & $\mathbf{t}_{\mathbf{R}}$ (min) & $\begin{array}{c}\text { Fatty acids as methyl esters } \\
\text { (FAMES) }\end{array}$ & $\begin{array}{c}\text { Short } \\
\text { names }\end{array}$ & $\mathbf{\%}$ \\
\hline 1 & 9.42 & Dodecanoic acid & $12: 0$ & 0.16 \\
\hline 2 & 12.35 & Tetradecanoic acid & $14: 0$ & 0.30 \\
\hline 3 & 13.76 & Pentadecanoic acid & $15: 0$ & 0.09 \\
\hline 4 & 15.14 & Hexadecanoic acid & $16: 0$ & 21.69 \\
\hline 5 & 15.86 & (Z)-9-Hexadecenoic acid & $16: 1$ & 1.05 \\
\hline 6 & 16.37 & Heptadecanoic acid & $17: 0$ & 1.82 \\
\hline 7 & 17.73 & (Z)-9-Octadecenoic acid & $18: 1$ & 54.93 \\
\hline 8 & 18.33 & Octadecanoic acid & $18: 0$ & 3.94 \\
\hline 9 & 19.29 & (Z,Z)-9,12-Octadecadienoic acid & $18: 2$ & 6.49 \\
\hline 10 & 20.06 & Eicosanoic acid & $20: 0$ & 1.06 \\
\hline 11 & 20.52 & (Z,Z,Z)-6,9,12-Octadecatrienoic & $18: 3$ & 2.08 \\
\hline 12 & 22.29 & acid & $22: 0$ & 0.85 \\
\hline 13 & 23.31 & Docosanoic acid & $20: 1$ & 2.05 \\
\hline 14 & 24.37 & Tetracosenoic acid & $24: 0$ & 0.26 \\
\hline
\end{tabular}

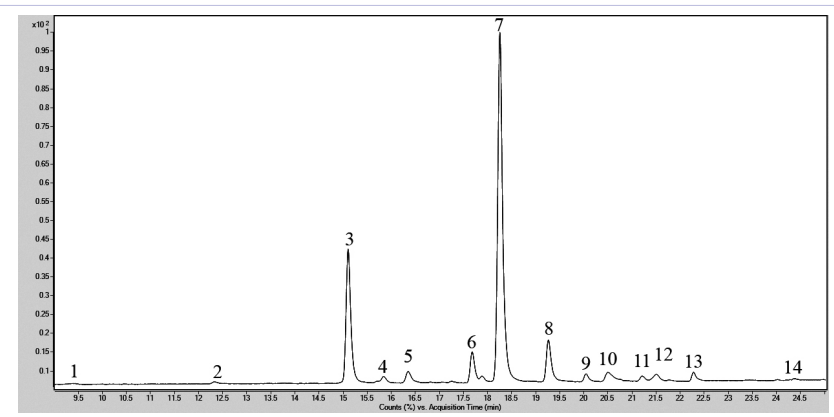

Figure 2: GCMS Total ions chromatogram (TIC) of carob FAMES, peak numbers and identifications are shown in Table 1.

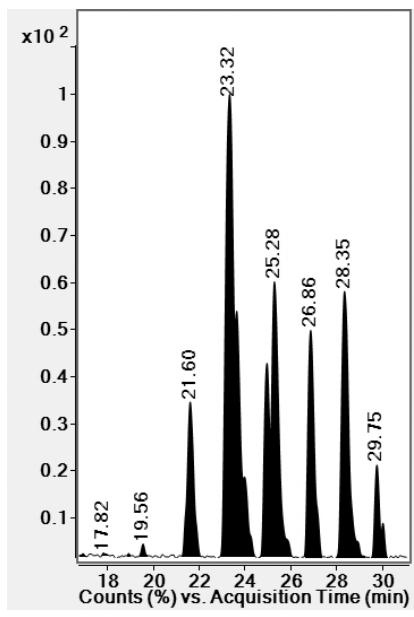

Figure 3: LCMS total ions chromatogram (TIC) of carob TAGs, peak numbers and identifications are shown in Table 2.

Table 2.Triacylglycerol (TAGs) composition and relative percentage of the carob pods, Peak numbers are those shown in Figure 2.

\begin{tabular}{|c|c|c|c|c|c|c|}
\hline \multirow{2}{*}{$\begin{array}{l}t_{\mathrm{R}} \\
(\mathrm{min})\end{array}$} & \multirow{2}{*}{$\begin{array}{l}\text { Accurate } \\
\text { Mass* }\end{array}$} & \multirow{2}{*}{$\begin{array}{l}\text { Identified } \\
\text { structures } \\
\text { (sn1, sn2, } \\
\text { sn3) }\end{array}$} & \multicolumn{2}{|c|}{$\begin{array}{l}\text { Loss of RCOOH } \\
\text { from }\end{array}$} & \multirow{2}{*}{ RCO+ } & \multirow{2}{*}{$\%$} \\
\hline & & & \begin{tabular}{|l|} 
sn1 \\
position
\end{tabular} & \begin{tabular}{|l|} 
sn3 \\
positions
\end{tabular} & & \\
\hline 17.58 & 901.7251 & $18: 2,18: 2,18: 2$ & $\begin{array}{l}621.4806 \\
18: 2\end{array}$ & $\begin{array}{l}621.4806 \\
18: 2\end{array}$ & $\begin{array}{l}263 \\
18: 2\end{array}$ & 0.07 \\
\hline 19.67 & 903.7418 & $18: 1,18: 2,18: 2$ & $\begin{array}{l}623.5020 \\
18: 2\end{array}$ & $\begin{array}{l}621.4806 \\
18: 1\end{array}$ & $\begin{array}{l}265 / 263 \\
18: 1 / 18: 2\end{array}$ & 0.27 \\
\hline 21.60 & 879.7426 & $16: 0,18: 0,18: 3$ & $\begin{array}{l}623.4707 \\
16: 0\end{array}$ & $\begin{array}{l}601.9316 \\
18: 3\end{array}$ & $\begin{array}{l}261 / 239 \\
18: 3 / 16: 0\end{array}$ & 7.26 \\
\hline 23.47 & 907.7743 & 18:1,18:1,18:1 & $\begin{array}{l}625.5150 \\
18: 1\end{array}$ & $\begin{array}{c}625.5150 \\
18: 1\end{array}$ & $\begin{array}{l}265 \\
18: 1\end{array}$ & 34.57 \\
\hline 24.95 & 935.8055 & 18:1,18:1,20:1 & $\begin{array}{l}653.5457 \\
18: 1\end{array}$ & $\begin{array}{l}625.5152 \\
20: 1\end{array}$ & $\begin{array}{l}293 / 265 \\
20: 1 / 18: 1\end{array}$ & 7.11 \\
\hline 25.26 & 909.7891 & 18:0,18:1,18:1 & \begin{tabular}{|l|}
627.5288 \\
$18: 1$
\end{tabular} & $\begin{array}{l}625.5151 \\
18: 0\end{array}$ & $\begin{array}{l}\text { 267/265 } \\
18: 0 / 18: 1\end{array}$ & 13.85 \\
\hline 26.88 & 937.8205 & 18:1,18:1,20:0 & $\begin{array}{l}655.5611 \\
18: 1\end{array}$ & $\begin{array}{l}625.5134 \\
20: 0\end{array}$ & $\begin{array}{l}\text { 295/265 } \\
20: 0 / 18: 1\end{array}$ & 10.61 \\
\hline 28.36 & 965.8523 & $18: 1,18: 1,22: 0$ & $\begin{array}{l}683.5962 \\
18: 1\end{array}$ & $\begin{array}{l}625.5150 \\
22: 0\end{array}$ & $\begin{array}{l}323 / 265 \\
22: 0 / 18: 1\end{array}$ & 14.07 \\
\hline 29.76 & 993.8852 & $18: 1,18: 1,24: 0$ & \begin{tabular}{|l|}
711.6209 \\
$18: 1$
\end{tabular} & $\begin{array}{l}625.5151 \\
24: 0\end{array}$ & $\begin{array}{l}351 / 265 \\
24: 0 / 18: 1\end{array}$ & 2.92 \\
\hline 30.02 & 967.8679 & $16: 0,20: 1,22: 0$ & \begin{tabular}{|l|}
711.6171 \\
$16: 0$
\end{tabular} & $\begin{array}{l}627.5321 \\
22: 0\end{array}$ & $\begin{array}{l}\text { 323/239 } \\
\text { 22:0/16:0 }\end{array}$ & 077 \\
\hline
\end{tabular}


positions of TAG, known as the sn1, sn2, or sn3 positions. The region specific analysis is restricted to determine the acylchains orientation as $\operatorname{sn} 1$ (3) and sn 2 positions. We have shown previously [13] that mass spectral fragmentation can provide information about the stereochemistry and region specific identification of the TAGs. Based on our finding on the fragmentation of standard authentic TAGs and available published work [13-15] that ions corresponding from the loss of fatty acids from the sn1and sn3 positions are much more abundance the ion corresponding to the loss of fatty acid at the sn2 position. In addition, the fact that each fatty acid chain produces an RCO+ ion, if two or three of the chains are different, two or three different $\mathrm{RCO}+$ are found but more for the sn 1 and sn 3 positions. Applying that information to the TAGs of carob Figure 3, the region isomers in the carob were identified as shown in Table 2.

\section{Phospholipids}

The LC-MS analysis of phospholipids of carob oil is presented in the Table 3 and Figure 4. On the basis of the mass fragmentation pattern of each component and the NIST library search, we found that carob oil contains one major phosphatidylcholine phosphor lipid (PC(O-18:1(9Z)/16:0)) representing 56.7\% of the identified phospholipids, two phosphatidylinositol phospholipids; PI18:0/0:0 (2.6\%), PI-20:1,11Z/22:0 (13.5\%),one phosphatidate phospholipidPA-20:0/22:0 (10.9\%)and one PG-16:0/21:0 (16.3), their chemical structures are shown in Figure 5.

\section{Unsaponifiable matters}

The GCMS analyses of the unsaponifiable matters of carob oil are presented in the Table 4 and Figure 6. On the basis of the mass fragmentation pattern of each component, the NIST library search, it was found that carob oil contains stigmasterol, $\beta$-sitosterol, $\gamma$-sitosterol, $5 \alpha$ - cholestan-3-one, betulin, $\beta$-amyrin, betulin free and squalene. Their structures are shown in Figure 7 and Figure 9.

\section{Head space volatile compounds}

The volatile emitted by fresh carob pod powder (Table 5) was analyzed by headspace followed by capillary gas chromatography and mass spectrometry Figure 8 . The headspace of carob pods is mainly constituted of monoterpenes and sesquiterpenes, and minor amounts of nonterpenoid aldehydes and hydro carbons. The identity of each compound was determined by comparison of its retention index relative to $\mathrm{C} 6-\mathrm{C} 24 \mathrm{n}$-alkanes, as well as of its

Table 3.Phospholipids composition and relative percentage of the carob pods

\begin{tabular}{|c|c|c|c|c|}
\hline $\begin{array}{c}t_{\mathrm{R}} \\
(\mathrm{min})\end{array}$ & $\begin{array}{c}\text { Accurate } \\
\text { Mass }\end{array}$ & Identified structures & Formula & \%* \\
\hline 9.61 & 585.4859 & PI(P-18:0/0:0) & $\mathrm{C}_{27} \mathrm{H}_{54} \mathrm{O}_{11} \mathrm{P}$ & $0.09(2.6)$ \\
\hline 10.04 & 799.6055 & PG(20:1(11Z)/18:3(6Z,9Z,12Z)) & $\mathrm{d}_{\mathrm{L}, \mathrm{H}_{70} \mathrm{O}_{10} \mathrm{P}}$ & $0.57(16.3)$ \\
\hline 11.35 & 746.5966 & $\mathrm{PC}(0-18: 1(9 \mathrm{Z}) / 16: 0)$ & $\mathrm{d}_{22} \mathrm{H}_{85} \mathrm{NO}_{7} \mathrm{P}$ & $1.98(56.7)$ \\
\hline 13.22 & 773.6264 & $\mathrm{PA}(\mathrm{P}-20: 0 / 22: 0)$ & $\mathrm{d}_{10} \mathrm{H}_{00} \mathrm{O}_{7} \mathrm{P}$ & $0.38(10.9)$ \\
\hline 14.49 & 949.6962 & $\operatorname{PI}(20: 1(11 Z) / 22: 0)$ & $\mathrm{q}_{1} \mathrm{H}_{08} \mathrm{O}_{12} \mathrm{P}$ & $0.47(13.5)$ \\
\hline
\end{tabular}

*Value is expressed as \% in the total lipid extract and values in prances are relative $\%$ in phospholipids fraction.

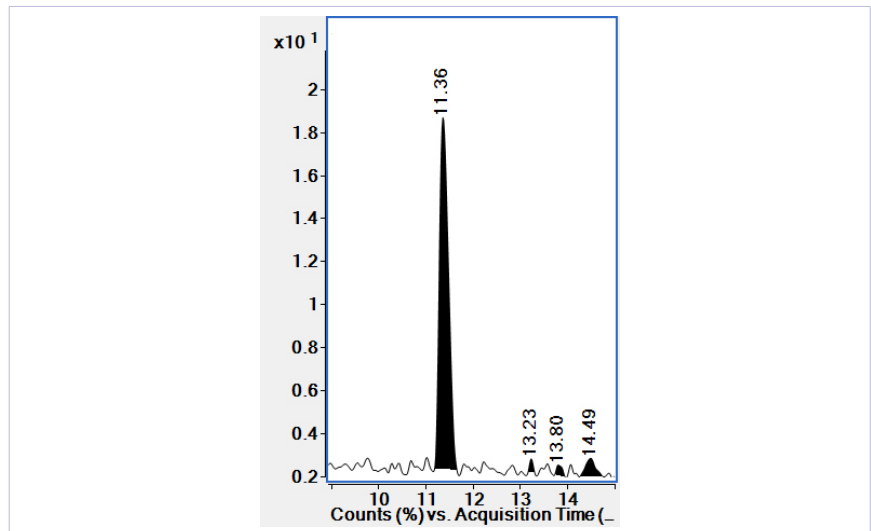

Figure 4: LCMS total ions chromatogram (TIC) of carob phospholipids, peak retention times $\left(t_{\mathrm{F}}\right)$ and identifications are shown in Table 3.

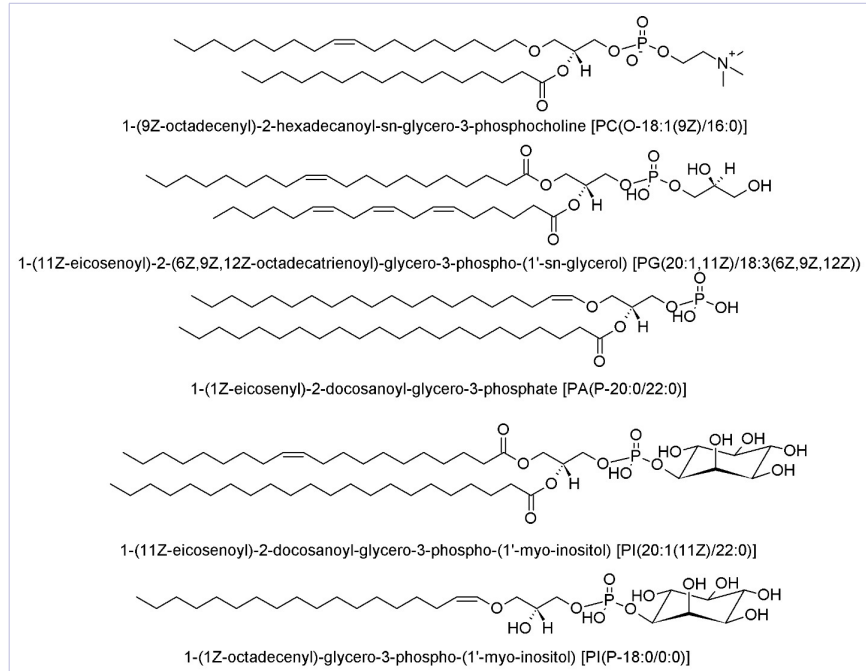

Figure 5: Phospholipids chemical structures that were identified in the carob pods

Table 4.Composition and relative percentages of the unsaponifiable matters of carob oil identified astrimethylsilyl ethers

\begin{tabular}{|l|l|l|l|l|l|}
\hline $\begin{array}{l}\mathrm{t}_{\mathrm{R}} \\
(\mathrm{min})\end{array}$ & Chemical Name & $\%$ & $\mathrm{t}_{\mathrm{R}}(\mathrm{min})$ & Chemical Name & $\%$ \\
\hline 8.31 & Stigmasterol & 8.39 & 9.67 & Betulin & 8.12 \\
\hline 8.92 & $\beta$-Sitosterol & 48.34 & 9.79 & $\beta$-Amyriner & 11.26 \\
\hline 9.25 & $\gamma$-Sitosterol & 1.71 & 10.25 & Betulin free & 1.36 \\
\hline 9.48 & $\begin{array}{l}5 \alpha \text {-Cholestan-3- } \\
\text { one }\end{array}$ & 3.12 & 10.97 & Squalene & 16.48 \\
\hline
\end{tabular}

spectral data with the Wiley's library spectral data bank (G1035B; Rev D.02.00; Agilent Technologies). For semi quantification purposes, the normalized peak area of each compound was used without any correction factors to establish abundances. The sesquiterpene compounds were present in higher abundant than monoterpenes.

\section{Conclusion}

This study has revealed qualitatively and quantitatively the 
particular compounds that make up the bulk of lipids in the carob fruit particularly the composition of the minor fractions, i.e. the profiles of phytosterols and other compounds more distinctly define the genuineness of individual oils and fats along with their respective fatty acid compositions. Carob pods are rich source of nutritional and health components, to extract those components,

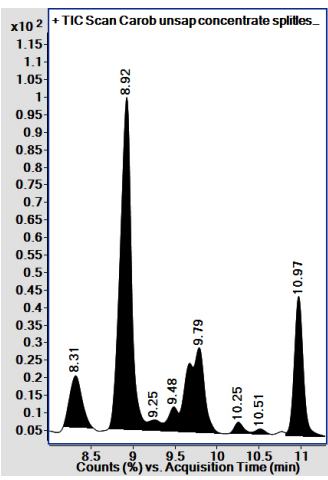

Figure 6: GCMS total ions chromatogram of the unsaponifiable matters of carob oil.

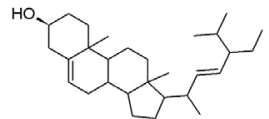

Stigmasterol

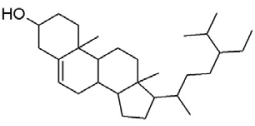

$\gamma$-Sitosterol

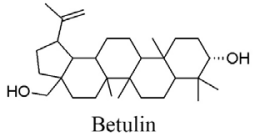

Betulin

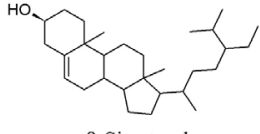

$\beta$-Sitosterol

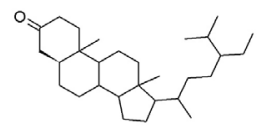

$5 \alpha$-Cholestan-3-one

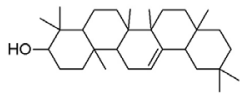

$\beta$-Amyrin

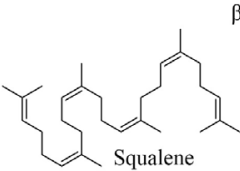

Figure 7: Chemical structures of the identified unsaponifiable matters of carob oil

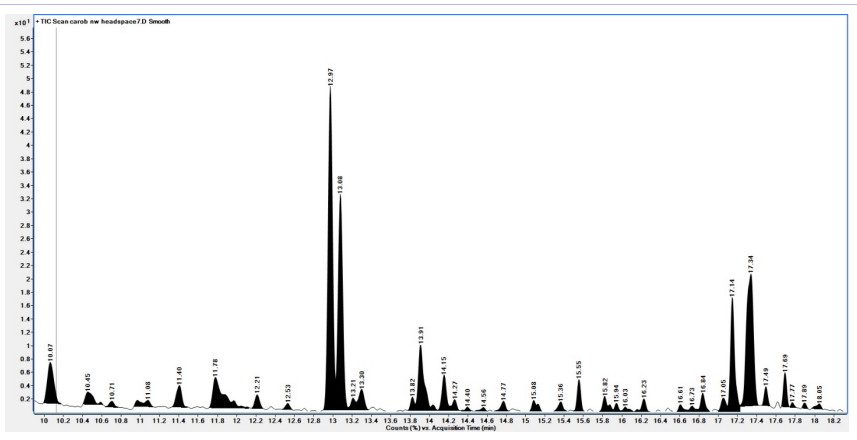

Figure 8: GCMS total ions chromatogram of the head space volatile components of the fresh carob pods powder.

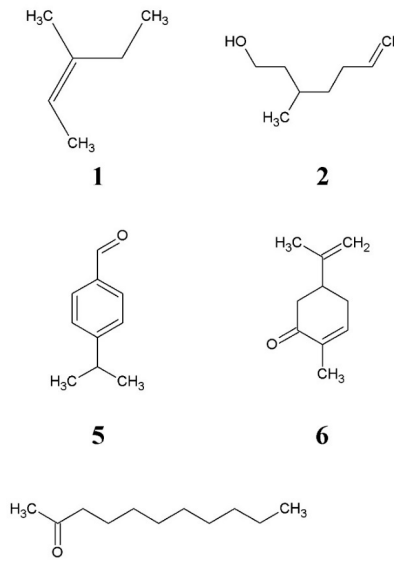

9

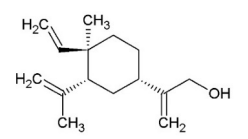

11
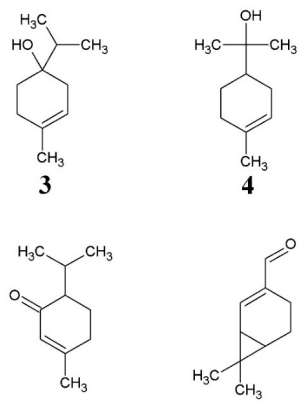

7

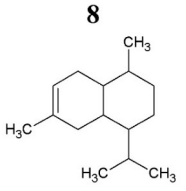

10

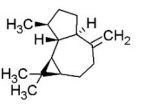

12

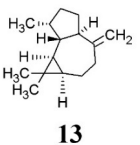

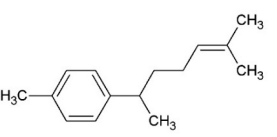

14

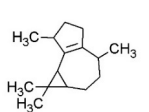

15

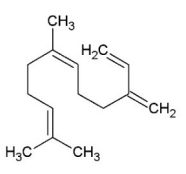

16
Figure 9: Chemical structures of the identified volatile compounds found in the head space of the fresh carob pods powder.

Table5. Composition and relative percentages of the head space volatile compounds of the fresh carob pods powder.

\begin{tabular}{|l|l|l|l|l|l|l|l|}
\hline$\#$ & $\begin{array}{l}\mathbf{t}_{\mathbf{R}} \\
\mathbf{( m i n )}\end{array}$ & Chemical names & $\%$ & $\#$ & $\begin{array}{l}\mathbf{t}_{\mathbf{R}} \\
\mathbf{( m i n )}\end{array}$ & Chemical names & $\%$ \\
\hline 1 & 10.07 & cis-3-methyl-2-pentene & 4.0 & 9 & 14.15 & 2-undecanone & 2.5 \\
\hline 2 & 10.45 & 3-methyl-6-hepten-1-ol & 1.5 & 10 & 15.55 & 3-cadinene & 1.7 \\
\hline 3 & 11.40 & terpinen-4-ol & 1.8 & 11 & 15.80 & $\begin{array}{l}\text { (-)-elema-1,3,11(13)- } \\
\text { trien-12-ol }\end{array}$ & 1.2 \\
\hline 4 & 11.78 & $\alpha$-terpineol & 5.1 & 12 & 16.84 & (+)-aromadendrene & 1.2 \\
\hline 5 & 12.97 & jopropylbenzaldehyde & 21.9 & 13 & 17.05 & aromadendrene & 1.0 \\
\hline 6 & 13.08 & (-)-carvone & 14.9 & 14 & 17.14 & $\alpha$-curcumene & 7.3 \\
\hline 7 & 13.30 & jiperitone & 1.8 & 15 & 17.34 & isoledene & 13.8 \\
\hline 8 & 13.91 & 2-caren-10-al & 6.0 & 16 & 17.69 & cis- $\beta$-farnesen & 3.5 \\
\hline
\end{tabular}

both a solubility and diffusivity of the extracting agent should be investigated. In order to facilitate the use of the extracts, it is important to carry out the extraction that allows for maximum amount of a particular component while minimizing or limiting the presence of other components. For that purpose, we used supercritical fluid extraction $\left(\mathrm{SCFE}-\mathrm{CO}_{2}\right)$ as a green technology to extract lipids from carob pods. Oils extracted by $\mathrm{SCFE}_{-} \mathrm{CO}_{2}$ showed similar quality, in terms of fatty acid composition than those obtained by traditional extraction techniques such soxhlet extraction using hazardous solvents like chloroform and methanol. Our study could be considered as the first detailed document on lipids profiling of carob pods. It showed that carob 
pods are very rich in oleic acid, but does not contain sufficient amounts of $\Omega-3$ polyunsaturated fatty acids to be considered as good nutritional oil.

Fatty acids, triacyclycerol, phospholipids, terpenoides, hydrocarbons and steroids pattern can be helpful for understanding of biosynthesis of TAG and establishing lipid profiling of plants is fundamentally important to gain insights of its lipid composition or lipidome.

\section{Acknowledgement}

This publication was made possible in part by research infrastructure support from grant number 2G12MD007605 from NIMHD/NIH.

\section{Disclaimers}

The views expressed in the submitted article are the authors own conclusion and not an official position of the institution or funder.

\section{References}

1. Santos M, Rodrigus A, Teixeira JA. Production of dextran and fructose from carob pod extract and cheese whey by Leuconostocmesenteroides NRRL B512 (f). Biochemical Engineering Journal. 2005;25(1):1-6. doi. org/10.1016/j.bej.2005.01.022.

2. Yousif AK, Alghzawi HM. Processing and characterization of carob powder. Food Chemistry. 2000;69(3):283-287. doi.org/10.1016/ S0308-8146(99)00265-4.

3. Khair M, El-Shatnawi J, Ereifej KI. Chemical composition and livestock ingestion of carob (Ceratonia siliqua L.) seeds. Journal of Range Management. 2001; 5(4): 669-673. doi:10.2458/azu_jrm_v54i6_elshatnawi.

4. Batlle I, Tous J. Properties, agronomy and processing. In: Carob tree Ceratonia siliqua L. IPGRI.CGIAR. Rome. Italy: 1997. P61-61.
5. Mulet A, Fernández-Salguero J, García-Pérez JV, Bon J. Mechanistic modeling to address process analysis: Kibbles of carob (Ceratonia siliqua, L.) pod extraction. Journal of Food Engineering. 2016;176:7176. doi.org/10.1016/j.jfoodeng.2015.06.011.

6. Burg B. Good treats for dog's cookbook for dogs: 50 Home-cooked treats for special occasions. Quarry Books. 2007;144.

7. Khalil MB, Hou W, Zhou H, Elisma F, Swayne LA, BlanchardAP et al Lipidomics era: Accomplishment sand challenges. Mass Spectrom Rev. 2010;29(6):877-929. doi: 10.1002/mas.20294.

8. Welti R, Li W, Li M, Sang Y, Biesiada H, Zhou HE. Profiling membrane lipids in plant stress responses. Role of phospholipase D alpha in freezing-induced lipid changes in Arabidopsis. J Biol Chem. 2002;277(35):31994-32002. doi: 10.1074/jbc.M205375200.

9. Akoh CC, Min DB. Food lipids, In: Chemistry, nutrition, and biotechnology 3th ed Marcel Dekker, Inc.New York. Basel. 2008.

10. Welti R, Shah J, Li W, Li M, Chen J, Burke JJ et al. Plant lipidomics: Discerning biological function by profilingplant complex lipids using mass spectrometry. Front Biosci. 2007;12:2494-506.

11. Nguyen T, Aparicio M, Saleh MA. Corchorus olitorius Linn: A Rich Source of $\Omega 3$-Fatty Acids. Pharm Anal Acta. 2016;7(6). pii: 486. doi: $10.4172 / 2153-2435.1000486$

12. Nguyen T, Aparicio M, Saleh MA. Accurate Mass GC/LC-Quadrupole Time of Flight Mass Spectrometry Analysis of Fatty Acids and Triacylglycerols of Spicy Fruits from the Apiaceae Family. Molecules. 2015;20(12):21421-32. doi: 10.3390/molecules201219779.

13. LawrenceS. Dasiah SKR, Sundaresan A, Arumughan C. A new method for simultaneous estimation of unsaponifiable constituents of rice bran. J Sep Sci. 2007;30(16):2786-93.doi: 10.1002/jssc.200700226.

14. Kalo P, Kemppinen A. Triglycerides/structures and properties. In: Encyclopedia of Food Sciences and Nutrition;Caballero, B., Trugo, L.P., Finglas, M., Eds.; Academic Press: London, UK, 2003; pp. 5857-5868.

15. Kuksis A, Itabashi Y. Regio and stereospecific analysis of glycerolipids. Methods. 2005;36(2):172-85. doi: 10.1016/j.ymeth.2004.11.001. 